\title{
HUBUNGAN BAHAYA LINGKUNGAN DENGAN RISIKO JATUH LANJUT USIA DI BPLU SENJA CERAH MANADO
}

\author{
Fani Dady, Herlina P. Memah, Jane A. Kolompoy* \\ Poltekkes Kemenkes Manado, Sulawesi Utara, Indonesia \\ *)E-mail: janiko.mvr@gmail.com
}

\begin{abstract}
ABSTRAK
Latar Belakang: Risiko jatuh pada lansia akibat kemunduran fisik, mental, dan sosial berpotensi menyebabkan cedera fisik. Faktor risiko jatuh pada lanjut usia dapat terjadi karena faktor intrinsik dan faktor ekstrinsik misalnya cahaya ruangan yang kurang terang, lantai yang licin, tersandung benda-benda, alas kaki kurang pas, turun tangga dan lain sebagainya. Tujuan: mengetahui hubungan bahaya lingkungan dengan risiko jatuh pada lanjut usia. Metode: survei analitik dengan desain Cross Sectional. Lokasi penelitian di BPLU Senja Cerah Manado. Teknik pengambilan sampel purposive non random sampling dan memenuhi syarat kriteria inklusi berjumlah 40 responden. Instrumen menggunakan kuesioner untuk bahaya lingkungan dan risiko jatuh Analisis data dilakukan menggunakan uji Statistik Chi-Square. Hasil penelitian: ada hubungan yang signifikan antara bahaya lingkungan dengan risiko jatuh berdasarkan uji statistik $\alpha=0,000 \leq 0,001$. Diskusi: Kondisi lingkungan fisik tempat tinggal yang berbahaya seperti tangga yang tidak ada pegangan, jalan yang tidak rata, pergantian ketinggian yang tidak memiliki tanda, tangga rusak, dan lantai licin, sangat berpotensi risiko jatuh pada lansia. Sebagian besar lansia yang mengalami kejadian jatuh memiliki kondisi lingkungan fisik rumah yang membahayakan. Kesimpulan: terdapat hubungan yang signifikan antara bahaya lingkungan dengan risiko jatuh. Faktor lingkungan yang kurang baik sangat berpotensi menyebabkan lansia mudah jatuh. Saran bagi petugas BPLU Senja Cerah Manado untuk memperhatikan lingkungan tempat tinggal lansia agar tidak berpotensi risiko jatuh, terutama meminimalkan bahaya lingkungan sehingga tidak berisiko jatuh pada lansia.
\end{abstract}

Kata Kunci: Bahaya lingkungan, risiko jatuh, lansia

\section{The Relationship of Environmental Hazard With The Risk of Falling in the Elderly at BPLU Senja Cerah Manado}

\section{ABSTRACT}

The risk of falling in the elderly due to physical, mental, and social decline has the potential to cause physical injury. Briefly the risk factors of falling in the elderly could be classified the intrinsic factor and extrinsic factors such as ligthning in the room which is not bright enough, slippery floor, tripping things, improper footwear, go down the stairs and so on. The purpose of this research is to know the relationship of environmental hazard with the risk of falling to the elderly. Method: The type of research is an analytical survey with Cross Sectional design. Research location is at BPLU Senja Cerah Manado. Sampling technique used is purposive nonrandom Sampling with 40 respondents. Questionnaire of environmental hazard dan risk of falling were used as instrument. Data processing is done by ChiSquare test. Results: there is an environmental hazard relationship with the risk of falling based on the statistical test of $\alpha=0,000 \leq 0,001$. Discussion: The hazardous physical environment of living such as stairs with no grip, uneven roads, altitude alters, broken stairs, slippery floors, are potentially risk of falling of the elderly. Most of the elderly who have fallen, have a dangerous house physical environment. Conclusion: It can be concluded that there is a relationship between environmental hazard and risk of falling. Advice for BPLU Officials of Senja Cerah Manado is to pay attention to the environment of elderly residents in order not to potentially risk of falling, especially minimizing environmental hazard so the elderly has not got any risk to fall.

Keywords: Environmental hazards, risk for falling, elderly 


\section{LATAR BELAKANG}

Dampak kemajuan ilmu pengetahuan dan teknologi (IPTEK), terutama di bidang kedokteran, berhasil menurunkan angka kematian bayi dan anak, memperlambat kematian, memperbaiki gizi dan sanitasi sehingga kualitas dan umur harapan hidup meningkat. Akibatnya, jumlah penduduk lanjut usia semakin bertambah banyak, bahkan cenderung lebih cepat dan pesat. Saat ini, di seluruh dunia, jumlah lanjut usia diperkirakan lebih dari 629 juta jiwa (satu dari 10 orang berusia lebih dari 60 tahun), dan pada tahun 2025 , lanjut usia akan mencapai 1,2 milyar (Nugroho, 2008).

Lanjut usia adalah bagian dari proses tumbuh kembang. Manusia tidak secara tiba-tiba menjadi tua, tetapi berkembang dari bayi, anak-anak, dewasa dan akhirnya menjadi tua. Semua orang akan mengalami proses menjadi tua dan masa tua merupakan masa hidup manusia yang terakhir. Dimasa ini seseorang mengalami kemunduran fisik, mental dan sosial secara bertahap (Azizah, 2011).

Penuaan penduduk terkait dengan transisi demografi dan epidemiologi lansia. Penuaan penduduk telah berlangsung secara pesat, terutama di negara berkembang pada dekade pertama abad milenium. Di Indonesia terjadi percepatan peningkatan penduduk lansia secara signifikan. Tercatat $7,18 \%$ (14,4 juta orang) di tahun 2000 dan diperkirakan akan menjadi 11,34\% (28,8 juta orang) pada tahun 2020 (Sunaryo, dkk, 2016).

Dampak demografi, umur harapan hidup, dapat terjadi masalah fisik, mental, sosial, serta kebutuhan pelayanan kesehatan dan keperawatan, terutama penyakit degeneratif. Sekitar $30-50 \%$ dari populasi lanjut usia (yang berusia 65 tahun) ke atas mengalami jatuh setiap tahunnya. Separuh dari angka tersebut mengalami jatuh berulang. Perempuan lebih sering jatuh dibandingkan dengan laki-laki.

Jatuh adalah suatu kejadian yang dilaporkan penderita atau saksi mata yang melihat kejadian, yang mengakibatkan seseorang mendadak terbaring/terduduk di lantai atau tempat yang lebih rendah dengan atau tanpa kehilangan kesadaran atau luka. Risiko jatuh merupakan peningkatan kemungkinan untuk jatuh yang dapat mengakibatkan cedera fisik. Secara singkat faktor risiko jatuh pada lanjut usia itu dapat digolongkan dalam dua golongan, yaitu faktor intrinsik (faktor dari dalam tubuh lanjut usia sendiri) misalnya gangguan jantung, gangguan sistem anggota gerak, gangguan sistem susunan saraf, gangguan penglihatan, gangguan pendengaran dan gangguan psikologis, sedangkan faktor ekstrinsik (faktor dari luar atau lingkungan) misalnya cahaya ruangan yang kurang terang, lantai yang licin, tersandung bendabenda, alas kaki kurang pas, turun tangga dan lain sebagainya (Azizah, 2011).

Penelitian yang dilakukan oleh Sutomo (2012) menunjukkan bahwa jatuh akibat faktor instrinsik yaitu lansia yang mempunyai gangguan jantung $(59,1 \%)$, gangguan gerak $(56,8 \%)$, gangguan susunan syaraf pusat/SSP $(63,6 \%)$, gangguan penglihatan (75\%). Sedangkan faktor ekstrinsik yaitu lansia yang mempunyai alat bantu berjalan $(54,5 \%)$ dan lingkungan (56,8\%). Dari hasil studi lapangan yang dilakukan oleh Sabatini (2016) disebutkan bahwa kejadian jatuh berdasarkan lokasi jatuh dan hampir jatuh yang disebabkan oleh faktor lingkungan tercatat sebanyak 77 kasus jatuh dan 24 kasus hampir jatuh.

Hutomo (2015) mengatakan bahwa jumlah penduduk yang usia lanjut antara usia 60 sampai 86 tahun sebanyak 42 lansia dengan angka kejadian jatuh sebanyak 26 lansia (57\%). Kejadian jatuh berdasarkan tempat kejadian terdiri dari: di dapur sebanyak 8 lansia (18\%), di kamar mandi 
sebanyak 7 lansia (16\%), di halaman rumah sebanyak 7 lansia (16\%), dan di kamar tidur sebanyak 4 lansia $(0,9 \%)$ dan yang tidak berisiko jatuh $11,9 \%$, berisiko jatuh $88,1 \%$.

Berdasarkan survey awal di Balai Pelayanan Lanjut Usia Senja Cerah Manado terdapat jumlah lansia yang berada di panti 60 orang namun ada sebagian yang minta izin pulang rumah. Di Balai Pelayanan Lanjut Usia Senja Cerah Manado terdapat 6 Wisma yaitu Ratulangi, Pejuang, Empat lima, Monginsidi, Proklamasi. Gedung setiap wisma terpisah satu dengan yang lain. Keadaan lingkungan tempat tinggal lansia, faktor penyebab jatuh lansia karena lingkungan atau ekstrinsik tempat tinggal lansia, keadaan jalan menuju wisma tidak rata dan menanjak, tidak ada pagar saat menuju ke wisma, tidak ada pegangan di WC/kamar mandi, tidak ada pegangan di dalam rumah, lantai kamar mandi/WC licin. Berdasarkan wawancara dengan lanjut usia yang berada di panti ada 4 orang yang menggunakan alat bantu jalan/tongkat dan terdapat 12 orang yang pernah mengalami jatuh per tahun, dan dari 12 orang ini pernah mengalami jatuh berulang akibat lingkungan yang berpotensi cedera.

Berdasarkan uraian di atas maka peneliti tertarik untuk melakukan penelitian "Hubungan Bahaya Lingkungan dengan Risiko Jatuh pada Lansia Balai Pelayanan Lanjut Usia Senja Cerah Manado". Tujuan penelitian untuk mengetahui hubungan bahaya lingkungan dengan risiko jatuh lansia di BPLU Senja Cerah Manado.

\section{METODE}

Penelitian ini adalah survey analitik dengan pendekatan Cross-Sectional. Populasi penelitian ini semua lanjut usia yang berada di Balai Pelayanan Lanjut Usia Senja Cerah Manado dengan jumlah 60 orang. Teknik pengambilan sampel dengan cara purposive non random sampling.
Kriteria inklusi lansia yang masih aktif, lansia dapat melakukan aktifitas dasar hidup sehari-hari, lansia menggunakan alat bantu tetapi masih mandiri, lansia yang mengalami gangguan penglihatan namun tidak perlu bantuan dan dapat berjalan sendiri, berada di panti saat penelitian, bersedia menjadi responden. Kriteria eksklusi adalah, Iansia yang menderita penyakit dan berada di tempat tidur, lansia yang menderita penyakit dan sementara dirawat.

Sampel dalam penelitian ini adalah responden yang memenuhi syarat kriteria inklusi berjumlah 40 orang. Alat ukur dalam penelitian ini menggunakan kuesioner untuk bahaya lingkungan dan risiko jatuh. Kuesioner bahaya lingkungan terdiri atas 14 pertanyaan dengan kategori penilaian dikatakan lingkungan yang tidak berbahaya seperti lantai rata dan tidak licin, penerangan dan pencahayaan baik, ada pegangan, WC/ kamar mandi tidak licin, tempat tidur tidak berada pada ketinggian, tidak ada barangbarang yang tergeletak di bawah lantai diberikan skor 1. Dikatakan lingkungan yang berbahaya seperti lantai tidak rata dan licin, penerangan dan pencahayaan kurang, tidak ada pegangan, WC/kamar mandi licin, tempat tidur terlalu tinggi, tersandung benda-benda diberikan skor 2 . Variabel bahaya lingkungan menggunakan instrumen lingkungan yang tidak berbahaya nilai: <mean. Dikategorikan lingkungan yang berbahaya nilai $\geq$ mean.

Variabel risiko jatuh merujuk pada Nursing Outcome Classification (Moorhead, dkk., 2013) dan telah dimodifikasi. Kuesioner resiko jatuh terdiri atas 14 pertanyaan. Keadaan dimana seseorang tanpa disadari mendukungnya terjadi jatuh. Tidak beresiko jatuh bila responden menjawab tidak pernah diberi skor 1 , dan jarang jatuh diberikan skor 2, sedangkan yang beresiko jatuh bila responden menjawab sering resiko jatuh diberikan skor 3 . Dikategorikan 
tidak beresiko jatuh nilai: < mean. Dikategorikan beresiko jatuh nilai: $\geq$ mean.

Analisis data menggunakan uji statistik Chi-Square untuk menganalisis hubungan bahaya lingkungan dengan risiko jatuh. Penelitian ini memiliki persetujuan etik dari Komite Etik Penelitian Kesehatan Poltekkes Kemenkes Manado dan ada ijin penelitian dari tempat melakukan penelitian yaitu BPLU Senja Cerah Manado pada bulan Juli 2017.

\section{HASIL}

Hasil penelitian yang menunjukkan karakteristik responden, yaitu umur dan jenis kelamin, ditampilkan pada diagram 1 dan 2 . Sedangkan distribusi bahaya lingkungan dan risiko jatuh ditampilkan di diagram 3 dan 4 .

Diagram 1. Distribusi Lanjut Usia Menurut Kelompok Umur di Balai Pelayanan Lanjut Usia Senja Cerah Manado

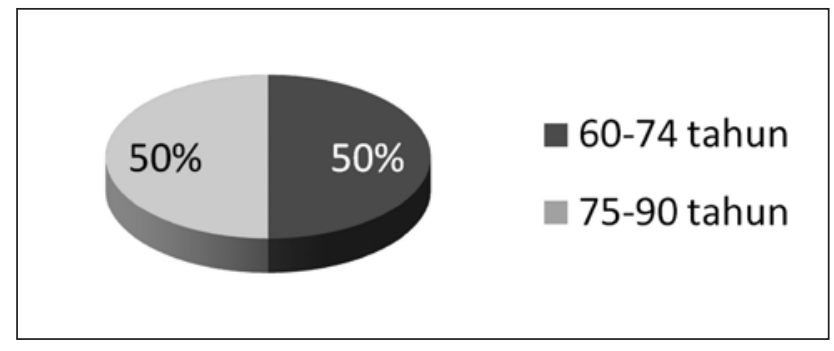

Diagram 1 di atas menunjukkan umur responden antara 60-74 tahun dan 75-90 tahun sama-sama sejumlah 20 responden (50\%).

Diagram 2. Distribusi Lanjut Usia Menurut Jenis Kelamin di Balai Pelayanan Lanjut Usia Senja Cerah Manado

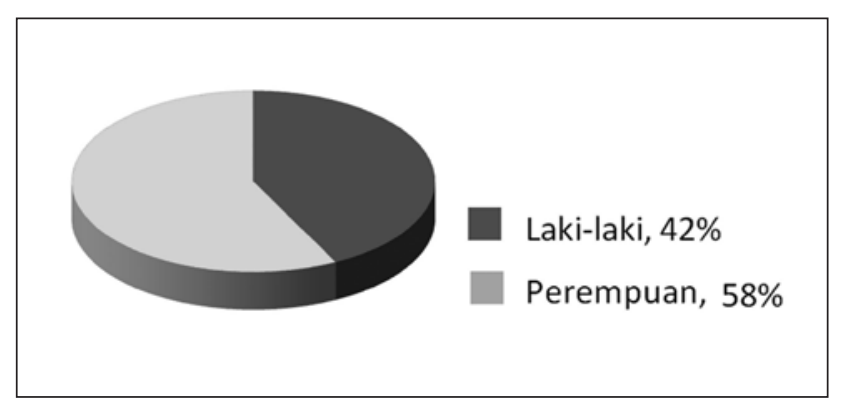

Diagram 2 di atas menunjukan jenis kelamin responden yang paling banyak adalah perempuan 23 responden (58\%).

Diagram 3. Distribusi Berdasarkan

Bahaya Lingkungan di Balai Pelayanan Lanjut Usia Senja Cerah Manado

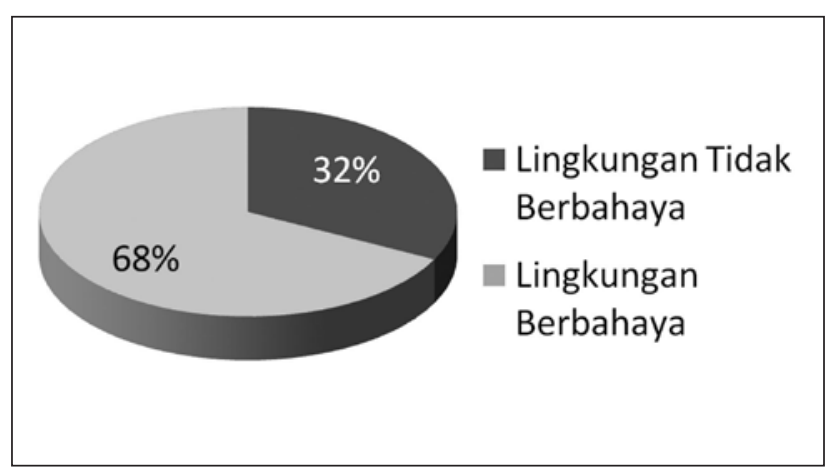

Diagram 3 di atas menunjukkan bahwa lingkungan tempat tinggal lansia yang berbahaya dilaporkan oleh 27 responden $(68 \%)$.

Diagram 4. Distribusi Berdasarkan Risiko Jatuh di Balai Pelayanan Lanjut Usia Senja Cerah Manado

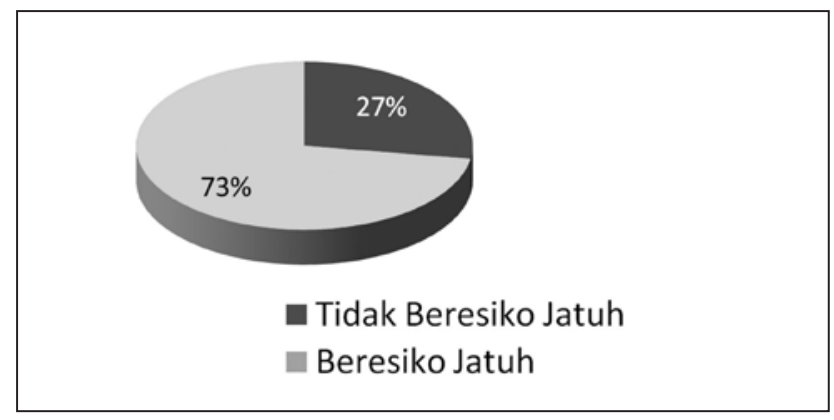

Diagram 4 di atas menunjukkan bahwa lansia yang berisiko jatuh sebanyak 29 responden $(73 \%)$. 
Tabel 1. Analisis Hubungan Bahaya Lingkungan Dengan Risiko Jatuh

\begin{tabular}{cccc}
\hline & \multicolumn{2}{c}{ Risiko Jatuh } & $\begin{array}{c}\text { Uji statistik } \\
\text { chi-square }\end{array}$ \\
\cline { 2 - 4 } $\begin{array}{c}\text { Bahaya } \\
\text { Lingkungan }\end{array}$ & $\begin{array}{c}\text { Tidak } \\
\text { Berisiko } \\
\text { Jatuh }\end{array}$ & $\begin{array}{c}\text { Berisiko } \\
\text { Jatuh }\end{array}$ & $p$ value \\
\cline { 2 - 4 } & $\mathrm{n} \quad \%$ & $\mathrm{n}$ & $\%$ \\
\hline
\end{tabular}

Lingkungan

$\begin{array}{llllll}\text { Tidak } & 9 & 68 & 4 & 32 & 0,000\end{array}$

berbahaya

Lingkungan

$\begin{array}{lllll}\text { Berbahaya } & 2 & 7 & 25 & 93\end{array}$

Tabel 1 menunjukkan bahwa bahaya lingkungan berhubungan dengan risiko jatuh pada lansia, setelah dilakukan uji statistik chi-square $\alpha=0,000 \leq 0,001$ jadi terdapat hubungan yang significant antara bahaya lingkungan dan risiko jatuh.

\section{DISKUSI}

Hasil penelitian ini menunjukkan bahwa ada 27 responden (68\%) yang melaporkan bahwa lingkungan tempat tinggal mereka berbahaya. Hal ini dipengaruhi oleh lansia yang kurang menjaga lingkungannya dengan baik sehingga memengaruhi lansia untuk berisiko jatuh. Lingkungan yang berbahaya yang didapat dalam panti yakni tidak ada pegangan di daerah tempat tidur, lantai kamar mandi/WC licin, tidak ada pegangan di daerah toilet dan bak mandi, tidak ada pegangan di tangga dan terdapat barangbarang yang tergeletak di lantai kamar tidur dan jalan di beberapa wisma menanjak, berbatuan dan tidak rata.

Ada 4 lansia yang berisiko jatuh meskipun lingkungannya tidak berbahaya, hal ini karena lansia tersebut mengalami penurunan fungsi penglihatan, gangguan pada sistem anggota gerak, dan karena ada faktor penyakit seperti asam urat dan hipertensi. Ada 2 lansia yang tidak berisiko jatuh meskipun lingkungannya berbahaya, hal ini karena fungsi kognitif dari lansia tersebut masih baik dan tidak ada gangguan pada sistem anggota gerak serta fungsi pendengaran dan fungsi penglihatan masih baik.

Untuk mencegah lingkungan rumah menjadi faktor risiko penyebab jatuh lansia, perlu dilakukan modifikasi lingkungan untuk mencegah risiko jatuh dengan cara mengidentifikasi dan memodifikasi lingkungan yang berbahaya seperti penerangan yang cukup, permukaan lantai tidak licin, perlengkapan perabot rumah, karpet, desain toilet perlu ada pegangan dan kloset duduk (Felmand \& Chaundhury, 2008).

Jatuh seringkali dialami oleh para lanjut usia dan penyebabnya bisa multifaktor, baik faktor intrinsik maupun faktor ekstrinsik misalnya cahaya ruangan yang kurang terang, lantai yang licin, tersandung bendabenda, alas kaki kurang pas dan sebagainya (Bandiyah, 2009).

Hasil penelitian ini sesuai yang dilakukan oleh Rondonuwu (2013) menyebutkan bahwa lingkungan yang tidak baik menyebabkan jatuh pada lansia sebanyak 10 responden $(26,3 \%)$ dibandingkan dengan lingkungan yang baik hanya menyebabkan jatuh pada lansia sebanyak 3 responden $(7,9 \%)$.

Berdasarkan diagram 4, lansia yang berisiko jatuh sebanyak 29 responden (73\%). Faktor lingkungan yang berpotensi bahaya pada lansia di panti yakni tidak ada pegangan di daerah tempat tidur, lantai kamar mandi/WC licin, tidak ada pegangan di daerah toilet dan bak mandi, tidak ada pegangan di tangga dan terdapat barangbarang yang tergeletak di lantai kamar tidur dan jalan di beberapa wisma menanjak, berbatuan dan tidak rata sehingga menyebabkan lansia berisiko jatuh.

Mayoritas tertinggi berisiko jatuh adalah perempuan sebanyak 23 responden (58\%) sedangkan laki-laki 17 responden (42\%). 
Berdasarkan data demografi komposisi jenis kelamin, lanjut usia perempuan sebesar $80 \%$, sedangkan lanjut usia laki-laki sebesar 20\%. Muhith dan Sandu (2016) menyatakan lansia perempuan memiliki skor risiko jatuh tertinggi dibanding lansia laki-laki. Hal ini karena lansia perempuan mengalami perubahan hormonal lebih awal yaitu mengalami menopause usia 45 tahun bandingkan laki-laki mengalami andropause sampai pada usia 70 tahun. Lansia kurang menjaga kesehatannya seperti jarang berolahraga, mengalami perubahan postur tubuh. Kepadatan tulang dapat berkurang, tulang belakang dapat memadat sehingga membuat tulang punggung menjadi terlihat pendek dan melengkung. Perubahan ini dapat mengakibatkan kerapuhan tulang sehingga terjadi osteoporosis. Kondisi ini membuat tulang menjadi keropos dan rentan retak sehingga menyebabkan lansia berisiko jatuh. Hal ini terjadi karena faktor hormonal dan kurangnya aktivitas fisik (Stanley, 2006). Hal ini ada kaitannya dengan data yang ditemukan berdasarkan frekuensi berulangnya jatuh, lanjut usia yang jatuh sebanyak 1 kali ada $60 \%$, jatuh 2 kali ada $12 \%$, jatuh 3 kali ada $16 \%$, jatuh 4 kali ada $8 \%$, dan jatuh 5 kali $4 \%$.

Berdasarkan faktor risiko, yang disebabkan oleh faktor intrinsik sebesar $60 \%$ dan faktor ekstrinsik sebesar 32\% (faktor intrinsik dan ekstrinsik sebesar 8\%). Sekitar 30$50 \%$ dari populasi lanjut usia (yang berusia 65 tahun) ke atas mengalami jatuh setiap tahunnya. Separuh dari angka tersebut mengalami jatuh berulang. Perempuan lebih sering jatuh dibandingkan dengan lanjut usia laki-laki (Nugroho, 2008).

Penelitian ini sesuai yang dilakukan oleh Rondonuwu (2013) yang menyebutkan bahwa lansia yang ketergantungan menyebabkan jatuh 10 responden $(26,3 \%)$, tidak jatuh 9 responden $(23,7 \%)$ dibandingkan dengan lansia yang mandiri menyebabkan jatuh 3 responden $(7,9 \%)$, tidak jatuh 16 responden (42,1\%). Penelitian ini ada kaitannya dengan penelitian yang dilakukan oleh Gunawan (2016) menunjukan bahwa lansia yang tergolong tidak aktif dalam beraktivitas mengalami risiko jatuh tinggi lebih banyak dengan jumlah 18 responden (43\%) dibandingkan dengan lansia yang tergolong aktif yang memiliki risiko jatuh tinggi lebih kecil sebanyak 6 responden (15\%).

Hasil penelitian ini menunjukkan adanya hubungan yang signifikan antara bahaya lingkungan dengan risiko jatuh. Dari hasil uji Chi Square diketahui lingkungan berbahaya yang menyebabkan risiko jatuh pada lansia lebih banyak dengan jumlah 25 responden $(92,6 \%)$ dibandingkan dengan lingkungan tidak berbahaya menyebabkan lansia berisiko jatuh dengan jumlah 4 responden $(30,8 \%)$. Hal ini menunjukkan bahwa lingkungan lansia yang kurang baik sangat berisiko lansia mudah jatuh. Lingkungan yang berpotensi berbahaya berada di panti yakni tidak ada pegangan di daerah tempat tidur, lantai kamar mandi/WC licin, tidak ada pegangan di daerah toilet dan bak mandi, tidak ada pegangan di tangga dan terdapat barang-barang yang tergeletak di lantai kamar tidur dan jalan di beberapa wisma menanjak, bebatuan dan tidak rata (Zein, 2016). Kemunduran fisiologis dapat mempengaruhi keselamatan lansia dikamar mandi seperti lantai licin, tidak ada pegangan.

Hasil penelitian di BPLU Senja Cerah Manado tentang bahaya lingkungan ada hubungan dengan risiko jatuh didapatkan hasil dengan menggunakan uji Chi-square $\alpha 0,000 \leq 0,001$. Hal ini dipengaruhi oleh lingkungan yang baik dan tidak berpotensi jatuh sedangkan lingkungan yang kurang baik sangat berpotensi jatuh (Anonim, 2015). Kamar tidur lansia, lantai terbuat dari bahan ubin biasa tidak licin dan mudah dibersihkan. Hindari potongan karpet kecil 
yang mudah tergelincir dan pastikan ujung karpet tidak tergulung keluar yang dapat menyebabkan lansia tersandung dan mudah jatuh. Penelitian ini juga mendukung penelitian lain tentang hubungan antara aktivitas fisik dengan risiko jatuh pada lanjut usia artinya ada hubungan yang sangat signifikan aktifitas fisik dengan risiko jatuh (Gunawan, 2016). Pencahayaan rumah tempat tinggal lansia memiliki jendela kaca yang berfungsi tempat masuk sinar matahari secara alami selain itu penerangan lampu yang terang di ruangan keluarga dan kamar mandi sedangkan di kamar tidur dilengkapi lampu tidur (Annas, 2013). Hal ini untuk meminimalkan risiko jatuh. Bahaya lingkungan yang termasuk berisiko jatuh pada lansia yaitu tangga yang tidak ada pegangan, jalan yang tidak rata, pergantian ketinggian yang tidak memiliki tanda, tangga rusak, kabel atau benda yang merintangi pejakan kaki (Solis, 2011). Hasil penelitian ini menunjukkan hubungan yang signifikan antara bahaya lingkungan dengan risiko jatuh sesuai dengan penelitian menurut Sofyan, Nugroho \& Astuti (2011) yang mengatakan bahwa ada hubungan yang signifikan antara kondisi lingkungan fisik rumah dengan kejadian jatuh pada lansia. Sebagian besar lansia yang mengalami kejadian jatuh memiliki kondisi lingkungan fisik rumah yang membahayakan.

\section{SIMPULAN}

Terdapat hubungan antara bahaya lingkungan dengan risiko jatuh. Sebagian besar lansia yang mengalami kejadian jatuh memiliki kondisi lingkungan fisik tempat tinggal yang membahayakan. Kondisi lingkungan fisik tempat tinggal yang berbahaya seperti yaitu tangga yang tidak ada pegangan, jalan yang tidak rata, pergantian ketinggian yang tidak memiliki tanda, tangga rusak, lantai licin, sangat berpotensi risiko jatuh pada lansia.
Berdasarkan hasil dari penelitian ini disarankan bagi petugas BPLU Senja Cerah Manado agar dapat memperhatikan lingkungan tempat tinggal lansia yang berpotensi bahaya lingkungan untuk mengurangi berisiko jatuh pada lansia. Untuk peneliti selanjutnya agar lebih mengembangkan penelitian ini pada tahap yang lebih spesifik seperti meminimalkan bahaya lingkungan mencegah risiko jatuh pada lanjut usia.

\section{DAFTAR PUSTAKA}

Annas, B.Q. (2013). Pencahayaan yang baik buat rumah lebih sehat. Jakarta: Harian ekonomi Neraca.

Anonim. (2015). Membuat kamar tidur yang nyaman untuk lansia. Jakarta: Architectaria.

Azizah. (2011). Keperawatan lanjut usia. Yogyakarta: Graha IImu.

Bandiyah, S. (2009). Lanjut usia dan keperawatan gerontik. Yogyakarta: Nuha Medika.

Feldman, F. \& Chaudhury, H. (2008). Falls and the physical environment: $A$ review and a new multifactorial falls-risk conceptual framework. Canadian Journal of Occupational Therapy, 7(2).

Gunawan, A. (2016). Hubungan antara aktivitas fisik dengan risiko jatuh pada lanjut usia di Desa Pucangan Kecamatan Kartasura (Skripsi). Fakultas IImu Kesehatan, Universitas Muhammadiyah Surakarta, Surakarta, Indonesia.

Hutomo, A.K. (2015). Hubungan penataan lingkungan rumah terhadap risiko jatuh pada lansia di desa Karang wuni Wates Kulonprogo (Skripsi). PSIK-Sekolah Tinggi IImu Kesehatan Aisyiyah, Yogyakarta, Indonesia. 
Moorhead, S., Johnson, M., Maas, M.L., \& Swanson, E. (2013). Nursing Outcomes classifition (NOC). Oxford, United Kingdom: Elsevier Global Rights Langford Lane.

Muhith, A., \& Sandu, S. (2016). Pendidikan keperawatan gerontik. Yogyakarta: Andi.

Nugroho, W. (2008). Keperawatan gerontik \& geriatrik, Edisi 3. Jakarta: EGC.

Rondonuwu, P.N. (2013). Hubungan status fungsional dan lingkungan dengan kejadian jatuh pada lanjut usia. Retrieved from http://kin.perpusnas. go.id

Sabatini, S. N. (2016). Risiko jatuh di teras dan kamar mandi rumah lansia, studi kasus: Yogyakarta. Bandung: Prosiding Temu IImiah IPLBI.

Sofyan A.I, Nugroho H.A, \& Astuti R., (2011) Hubungan antara kondisi lingkungan fisik rumah dengan kejadian jatuh pada lansia di kelurahan Ngijo Gunung Pati Semarang. Jurnal Keperawatan Fikkes, 4(1).
Solis, H.L. (2011). Slips, trips \& all. United States of America: Department of Labour.

Stanley, M. \& Beare, P.G. (2006). Gerontological Nursing: A Health Promotion Protection Approach. Edisi 2. (Alih bahasa: Nely Yuniarti, Sari Kurnianingsih). Jakarta: Penerbit Buku Kedokteran EGC.

Sunaryo, Wijayanti, R., Kuhu, M.M., \& Sumedi, T. (2016). Asuhan keperawatan gerontik. Yogyakarta: Andi.

Sutomo. (2012). Analisis faktor-faktor yang berhubungan dengan risiko jatuh pada lansia di Panti Werdha Wisma Mulia Jakarta Barat (Tesis). Universitas Esa Unggul, Jakarta, Indonesia.

Zein, A.O.S. (2016). Kemunduran fisiologis lansia dan pengaruhnya terhadap keselamatan di kamar mandi Studi Kasus Kamar Mandi Panti Wredha Asuhan Bunda. Bandung: Itenas Library. 